\title{
FORMAÇÃO DE RECURSOS HUMANOS \\ PARA O ATENDIMENTO A SAÚDE \\ DA CRIANÇA DE 0 A 6 ANOS
}

\author{
FORMATION DE PERSONNEL DE SANTÉ DESTINES \\ À LA PRISE EN CHARGE DE L'ENFANT DE 0 A 6 ANS
}

Antonio Marcio Junqueira Lisboa ${ }^{1}$

LISBOA, A.M.J. Formação de Recursos Humanos para o Atendimento à Saúde da Criança de 0 a 6 anos. Rev. Bras. Cresc. Des. Hum. Ill(l): São Paulo, 1993.

\section{RESUMO}

O autor aponta para a necessidade de uma visão holística e ecológica bio-psico-social da criança, se se quiser garantir o desenvolvimento físico, psíquico e social harmonioso. Define a Pediatria como o ramo da Medicina que se ocupa do crescimento e do desenvolvimento do ser humano, da concepção à adolescência, quer tratando, quer prevenindo, quer corrigindo condições desviantes.

A perda da percepção holística da pessoa criou profissionais e um sistema de ensino que privilegia uma visão fragmentada do ser humano visto como 6rgãos e aparelhos, sem compromisso social e sem levar em conta a relação médico-paciente. O ensino é caracterizado pela desintegração inter-institucional de programas de formação e de capacitação de recursos humanos, e ainda pela falta de uma visão balística das necessidades infantis e da realidade social.

O autor advoga uma completa reformulação da situação existente, oferecendo requisites para programas de formação e capacitaÇãO de recursos humanos para o atendimento da criança de 0 a 6 anos.

\section{RÉSUMÉ}

L'auteur signale la nécessité d'une vision globale de l'enfant, si l'on souhaite assurer un développement physique, psychique et social harmonieux. 11 définit la Pediatrie comme une branche de la Médecine qui s'occupe de la croissance et du développement de l'être humain, depuis sa conception jusqu'à l'adolescence, eu assurant te traitement, la prévention, ou en corrigeant certains conditions déviantes.

La perte d'une perception holistique de l'individu a crée des professionnels et un système d'enseignement qui privilegie une vision fragmentée de l'être humain vu comme un ensemble d'organes et d'appareils, sans rôles social et ignorant le rapport médecin-malade. L'enseignement est caracterisé par la désintégration inter-institutionnelle des programmes de fom^lation de personnel, et par le manque d'une vision globale des besoins de l'enfant et de la réalité sociale.

L'auteurplaide pourune réorganisation de la situation actuelle, en précisant les conditions requises pour les programmes de formation de personúel de santé destinés a prendre en charge l'enfant de 0 à 6 ans.

1 Professor Titular de Pediatria da Universidade de Brasília. 
Um dos objetivos mais importantes dos programas de atenção à saúde da criança é garantir o seu desenvolvimento harmonioso, tanto no aspecto físico como no psicológico e no desempenho social.

A Pediatria é o ramo da Medicina que se ocupa do crescimento e desenvolvimento humanos, tanto no que se refere aos aspectos de sua normalidade quanto da prevenção e da correção das condições que possam desviá-los dessa nommalidade.

Dentro desse conceito a abrangência da Pediatria vai da concepção à adolescência, o que implica no conhecimento das peculiaridades e necessidades do feto, do recém-nascido, do lactente, do pré-escolar, do escolar e do adolescente. Embora diferentes, cada um deles deve ser considerado no seu sentido holistico, ou seja, como uma unidade bio-psico-social, interagindo continuamente com o meio, com sua família e com sua comunidade, que apresentam caracteristicas sócio-culturais e econômicas específicas.

Durante seus primeiros anos de vida a criança é totalmente dependente. Para que cresça e se desenvolva corretamente, necessita do apoio e do carinho das pessoas que a cercam. Essa dependência toma de extrema importância o relacionamento criança-mãe-pai-fam lia-comunidade.

Cada um desses periodos apresenta riscos específicos. O neonatal, por exemplo, é caracterizado pelas altas cifras de mortalidade e morbidade. Todos os esforços são dirigidos à prevenção da morte e dos danos neuro16gicos que possam comprometer a qualidade de vida futura. O período critico em relação à formação da personalidade é representado pelos primeiros seis anos de vida, o que justifica a frase-impacto do médico e educador inglês DODSON - 'judo está em jogo antes dos seis anos".

A criança atinge metade de sua estatura de adulto entre 2 a 3 anos; seu cérebro alcança $90 \%$ de seu tamanho final até os 5 anos; seu desenvolvimento intelectual está praticamente estruturado em $50 \%$ até os 4 anos e em $80 \%$ até os anos e sua estrutura de comunicação linguística está formada até os 3 anos. Ao atingir 3 anos já terá passado por vivências marcantes para a formação de sua auto-imagem, que são fundamentais para seu futuro como cidadão na comunidade em que vive. Estima-se em 25.000.000 o número de crianças de 0 a 6 anos no Brasil. Sua alta vulnerabilidade bio-psico-social pode ser constatada:

1 - pelas altas cifras de mortalidade. Morrem cerca de 320.000 crianças de 0 a 5 anos no Brasil, a cada ano, grande partepor desnutrição, infecções e causas perinatais, passíveis de prevenção ou tratamento com a utilização de medidas simples e de baixo custo;

2 - pelas altas cifras de morbidade. Aproximadamente $30 \%$ das internações na rede hospitalar da Previdência Social são de crianças abaixo de 2 anos, a maioria vítimas de desnutrição como causa primária ou associada;

3 - pela imaturidade biológica;

4 - pela necessidade que têm de receber do meio ambiente estímulos essenciais ao seu desenvolvimento;

5 - pelo abandono a que são relegadas grande parte delas;

6 - pela necessidade crescente de suas mães ingressarem no mercado de trabalho;

7 - pela deficiência quantitativa e qualitativa de recursos humanos capacitados para o seu atendimento;

8 - pela falta de integração intra e inter-institucional de programas de formação e de capacitação de recursos humanos que irão se dedicar ao seu atendimento;

9 - pela falta de uma visão holistica ao atendimento de suas necessidades;

10 - pela falta de conhecimento por parte de profissionais de saúde, da população e da sociedade como um todo de que problemas considerados da mais alta gravidade como violência, delinquência, prostituição, corrupção, só serão controlados à medida que consigamos formar bons cidadãos, o que passa obrigatória e $\mathrm{pr}^{\wedge} \mathrm{i}^{\wedge}$ oritaria mente pelo atendimento das necessidades das crianças até 6 anos.

\section{Situação atual da formação de recursos humanos}

O médico de criança precisa ter a experiência de um atilado clínico a vivência de um pedagogo, a sabedoria de um filósofo, visão de um sociólogo e principalmente profundo amor pelas crianças.

Duas figuras exponenciais do século XVIIRENÉDESCARTES e ISAAC NEWTON foram os pais da revolução científica que tratou de substituir a concepção organica da natureza pela metáfora do mundo como máquina. O método de DESCARTES é analítico, que consiste em decompor o todo em partes e em dispô-las em uma ordem lógica. Foi ele que tornou possível a chegada do homem à Lua. Entretanto foi excessiva a ênfase dada ao método cartesiana que levou a fragmentação de nossas disciplinas académicas e à 
atitude generalizada de reducionismo na ciência que contribuíram decisivamente para se perder a noção holistica tão importante na solução de uma série de problemas, em especial na área da saúde e em particular na criança. DESCARTES começou privilegiando à mente sobre a matéria, "não há nada no conceito de corpo que pertença à mente, e nada na idéia de mente que pertença ao corpo”. O pensamento cartesiana modificou profundamente o pensamento ocidental. Na área de saúde, por exemplo, impediu que os médicos levassem seriamente em consideração os aspectos psicológicos das doenças e os psicólogos considerassem a importancia da saúde física sobre a mente. Estavam definitivamente separados corpo e mente.

Para DESCARTES o universo material era uma máquina. A cuidadosa descrição dos componentes dos organismos vivos têm sido a principal tarefa de biólogos, médicos e psicólogos nos últimos trezentos anos. As consequências adversas dessa falácia reducionista tornaram-se especialmente evidentes na medicina, onde a adesão ao modelo cartesiano impediu que médicos compreendessem muitas das mais importantes enfermidades.

ISAAC NEWTON, nascido em 1642, deu realidade ao sonho cartesiana e completou a revolução científica. A imagem do mundo como uma máquina perfeita, que tinha sido introduzida por DESCARTES, passou a ser um falo comprovado e NEWTON o seu símbolo. Os pensadores do século XVIII passaram a aplicar os princípios da mecanica newtoniana às ciências da natureza e da sociedade humana, logicamente ai incluída a medicina. A influência do pensamento cartesiano-newtoniano persiste até hoje. Estuda-se o ser humano como se fosse uma máquina. Na anatomia se estudam as peças; na fisiologia como elas funcionam; na biofísica como circulam os fluidos; na bioquímica como se dão as reações; na patologia o que ocorre quando estas funcionam mal, e assim por diante. E o conjunto? O curriculo das escolas médicas ficou pulverizado em disciplinas, cada uma delas dedicada a uma peça da estruturahumana. Perdeu-se a visão holística da pessoa que pensa, sonha, sofre, vive no seio da sua família e interage com seu meio ambiente. Cria-se um profissional com a visão fragmentada dos 6rgãos e aparelhos que constituem o ser humano. Embora os progressos no sentido tecnológico sejam inegáveis, vem perdendo a Medicina duas de suas mais belas dimensões: o seu compromisso social e a relação médico-paciente.

A situação em que vivemos é caracterizada por uma perda sensível da eficiência do ensino. A proliferação de disciplinas facilitou o paralelismo, a superposição e as contradições de seus conteúdos. Tornando-se verdadeiros feudos as discipli- nas não autõno m as. Ensina-se cardiologia como se existisse um coração de forma isolada. O mesmo se passa em relação aos outros 6rgãos e aparelhos. A falta de comunicação entre as diferentes disciplinas, mesmo na mesma área de conhecimento é quase total, o que dificulta e até impede qualquer processo de coordenação.

Em sua corrida diária para frequentar as disciplinas e conseguir os créditos, o treinamento em serviço tornou-se impraticável, inclusive no internato. O relacionamento médic b paciente, básico para o exercício da prática médica tornouse quase impossível. O eixo de preocupação dos alunos desloca-se progressivamente da necessidade de aquisição de competências para o da obtenção de créditos. O aluno passa ser avaliado através de testes de múltipla- escolha e não pela sua capacidade de solucionar problemas, pela sua formação ética e pelo seu embasamento científico.

Acredito que a mesma situação que vem ocorrendo na área médica seja encontrada em outras áreas que se dedicam à saúde, como enfermagem, psicologia, odontologia, serviço social. Se a desintegrarão intrainstitucional é grande, imagina-se o que se passa quando se tem necessidade da utilização de várias intituições para que determinadas competências sejam adquiridas.

Para que se forme ou se capacitem recursos humanos para o atendimento das necessidades da saúde da criança de $\mathrm{O}$ a 6 anos haveria necessidade de uma completa reformulação da situação existente.

\section{Requisites para os programas de formação e capacitação de recursos humanos para o atendimento da criança de 0 a 6 anos}

Os programas para o atendimento das necessidades de saúde das crianças de $\mathrm{O}$ a 6 anos devem levar em consideração que:

1. A criança é uma unidade bio-psico-social e deve ser atendida dentro de um conceito holístico e ecológico;

2. Os pais deverão participar ativamente do processo, bem como a família e eventualmente, a própria comunidade;

3. A aquisição de conhecimentos e competências deve ser feita sob a forma de treinamento em serviço;

4. As instituições formadoras de recursos humanos deverão utilizar equipes multidisciplinares e multiprofissionais para o ensino;

5. A convivência de alunos de diferentes cursos profissionalizantes no processo de formação ou capacitaçã^O, além de ser recomendável dará a eles uma visão bem mais completa das necessida- 
des da criança e das vantagens e importância do trabalho em equipe;

6. A formação e a capacitação não é eficiente quando se utiliza o modelo cartesiana ou disciplinar. Deverá ser estimulado o modelo programático, já utilizado na Faculdade de Ciências da Saúde da Universidade de Brasília no denominado Programa de Assistência Integral à Saude da Criança, que contava com a participação de pediatras, especialistas e cirurgiões pediátricos, assistente social, enfermeiros, psicólogos e nutrólogos em seu corpo docente, com resultados excepcionais;

7. Existe uma real necessidade do ensino estar ligado à prática, o que torna recomendável que o processo de capacitação se faça através da utilização de áreas de integração docente-assistencial, mesmo porque o trabalho é o grande aglutinador para a formação de equipes multiprofissionais e para a aprendizagem interdisciplinar. 